\title{
PENENTUAN JUMLAH PRODUKSI SHAMPO DENGAN FUZZY INFERENCE SYSTEM SUGENO: STUDI KASUS PT. GUARDIAN PHARMATAMA TANGERANG
}

\author{
Ri Sabti Septarini \\ Universitas Muhammadiyah Tangerang / Fakultas Teknik, \\ Program Studi Informatika \\ Jl. Perintis Kemerdekaan 1/33 Cikokol Kota Tangerang TLP. 55793251, 55772949, 55793802, 55736926 \\ e-mail: risabtis@ft-umt.ac.id
}

\begin{abstract}
Human are always faced with taking a decision. It also happens to a company in the process of determining which employees. In determination the production plan required a lot of considerations in case of taking decisions. Beside that, the number of employees in a company is to determine who get the production plan of the achievement. System is made to determine employees who will get benefits achievement based on the some criteria have been determined by the company. These criterias will be used as fuzzy input which also process a called fuzzy variables. In this research will construct decision support system by using fuzzy logic with fuzzy variables input that are productivity, quality tabbing and discipline. In of fuzzy logic method there are three stages, namely stage fuzzification, inference and deffuzification. At this stage of the fuzzy inference used the Sugeno method. The results of this experiments has performed that the system is able to display the production planning data for the calculation of the value of production that have been determined based on fuzzy logic with fuzzy variables.
\end{abstract}

\section{Keyword: Decision Support System, Fuzzy Logic, Sugeno.}

\section{A. PENDAHULUAN}

Era persaingan yang semakin ketat pada saat sekarang ini telah menyebabkan perusahaan-perusahaan yang bergerak di bidang industri khususnya dalam bidang industri makanan harus semakin spesifik dalam menentukan kelangsungan hidup perusahaannya agar mampu bertahan. Hal ini mengharuskan perusahaan untuk merencanakan atau menentukan jumlah produksi, agar dapat memenuhi pemesanan pasar dengan tepat waktu dan dengan jumlah yang sesuai, sehingga diharapkan keuntungan perusahaan akan meningkat.

Penentuan jumlah produksi dalam perusahaan merupakan suatu hal yang harus diperhatikan sebelum memulai sebuah proses produksi. Perlu dipertimbangkan berbagai faktor untuk menentukan jumlah produksi barang, untuk menghindari resiko perusahaan. Untuk menyelesaikan masalah tersebut, pihak perusahaan, dalam hal ini manajer, hendaknya dapat membuat suatu keputusan yang tepat untuk memilih berapa banyak jumlah produk yang diproduksi untuk mengoptimalkan keuntungan suatu perusahaan. Maka, dibutuhkan suatu sistem pendukung keputusan untuk membantu para manajer tersebut.

Dari masalah optimasi produksi barang tersebut, banyak metode maupun teknik yang digunakan. Metode yang paling sering digunakan adalah logik himpunan tegas. Akan tetapi logika himpunan tegas tidak dapat dioperasikan atau digunakan oleh khalayak umum (hanya orang analisis), karena selain agak rumit dalam penghitungan, kendala-kendala dalam produksi juga akan memperumit penyelesaian masalah optimasi produksi barang. Selain logika himpunan tegas, logika fuzzy juga dapat digunakan dalam masalah optimasi produsi barang.

Logika fuzzy dianggap mampu untuk memetakan suatu input ke dalam suatu output tanpa mengabaikan faktor-faktor yang ada. Logika fuzzy diyakini dapat sangat fleksibel dan memiliki toleransi terhadap data-data yang ada. Dengan berdasarkan logika fuzzy, akan dihasilkan suatu model dari suatu sistem yang mampu memperkirakan jumlah produksi. Faktor- 
faktor yang mempengaruhi dalam menentukan jumlah produksi dengan logika fuzzy antara lain jumlah pemesanan dan jumlah persediaan.

\section{B. IDENTIFIKASI MASALAH}

Berdasarkan uraian latar belakang, dapat diidentifikasi permasalahannya adalah optimasi perkiraan produksi barang berdasarkan logika fuzzy dengan memperhatikan faktor jumlah permintaan dan jumlah persediaan.

\section{RUMUSAN MASALAH}

Berdasarkan pemikiran diatas maka rumusan masalahnya adalah:

1. Bagaimana penerapan metode Sugeno untuk menentukan jumlah produksi Fungasol SS Shampo berdasarkan data persediaan dan jumlah permintaan?

2. Bagaimana mengembangkan sebuah sistem pendukung keputusan dengan metode Sugeno untuk menentukan jumlah produksi barang berdasarkan data persediaan dan jumlah permintaan?

3. Bagaimana tingkat validitas sistem pendukung keputusan metode Sugeno dengan berbagai model defuzzifikasi dalam menentukan jumlah produksi berdasarkan data persediaan dan jumlah permintaan?

\section{BATASAN MASALAH}

1. Produk yang diteliti adalah Fungasol SS Shampo untuk tahun 2010-2012.

2. Banyaknya variabel dalam pengambilan keputusan produksi barang ada 3 macam, yaitu permintaan, persediaan, dan produksi barang.

3. Metode yang digunakan adalah dengan pendekatan Fuzzy Sugeno.

4. Perangkat lunak sebagai pendukung adalah aplikasi MATLAB \& Simulink Release 2011a

5. Metode Max Min digunakan untuk komposisi antar-aturan.

6. Metode Moving Averrage digunakan untuk defuzzy.
7. Sebagai input akan dipergunakan data persediaan dan data pemesanan.

\section{E. TINJAUAN PUSTAKA}

Sistem Pendukung Keputusan

Istilah Decision Support System (DSS) atau Sistem Pendukung Keputusan baru mulai dipopulerkan pada tahun 1971 oleh Gorry dan Morton. Mereka mendefinisikan Sistem Pendukung Keputusan sebagai "suatu sistem interaktif berbasis komputer yang dapat membantu para pengambil keputusan dalam menggunakan data dan model untuk memecahkan persoalan yang bersifat tidak terstruktur" (McLeod, 2004). Sedangkan menurut Surbakti (2002:2), Sistem Pendukung Keputusan didefinisikan dengan "Sistem berbasis komputer yang interaktif yang membantu pengambil keputusan memanfaatkan data dan model untuk menyelesaikan masalah-masalah yang tidak terstruktur. DSS mendayagunakan sumber daya individu-individu secara intelek dengan kemampuan komputer untuk manajemen pengambilan keputusan yang berhubungan dengan masalah-masalah yang semi terstruktur" .

Berdasarkan pernyataaan-pernyataan tersebut, maka dapat didefiniskan bahwa terdapat empat karakteristik utama dari suatu Sistem Pendukung Keputusan yaitu :

1. Sistem Pendukung Keputusan menggabungkan data dan model menjadi satu bagian.

2. Sistem Pendukung Keputusan dirancang untuk membantu para manajer (pengambil keputusan) dalam proses pengambilan keputusan dari masalah yang bersifat semi struktural.

3. Sistem Pendukung Keputusan lebih cenderung dipandang sebagai pendukung penilaian manajer dan sama sekali bukan untuk menggantikannya.

4. Teknik Sistem Pendukung Keputusan dikembangkan untuk meningkatkan efektifitas dari pengambil keputusan (Marimin, 2004).

\section{Fase Pengambilan Keputusan}

Model Simon adalah model yang paling singkat dan memenuhi karakteristik rasional dalam pengambilan keputusan. 
1. Fase Intelligence Intelligence dalam pengambilan keputusan meliputi analisa lingkungan, baik secara bertahap maupun berkesinambungan. Termasuk kegiatan mengidentifikasi masalah atau kesempatan (Termasuk juga memonitor hasil dari fase implementasi).

2. Fase Design

Fase ini meliputi kegiatan menemukan atau mengembangkan dan menganalisa kemungkinan alternatif solusi. Termasuk kegiatan memahami masalah dan menguji beberapa kemungkinan solusi. Sebuah model dari masalah dalam pengambilan keputusan dibangun, diuji dan divalidasi. Membuat model meliputi kegiatan mengkonseptualisasikan masalah dan menyederhanakannya kedalam bentuk kualitatif dan/atau kuantitatif.

\section{Fase Choice}

Choice adalah tahapan kritis dalam pengambilan keputusan. Pada fase inilah keputusan sebenarnya dibuat dan komitmen untuk mengikuti arah tertentu dari tindakan yang telah terpilih dilakukan. Batasan antara fase design dan fase choice seringkali tidak jelas karena ada beberapa aktivitas tertentu dapat dilakukan dalam kedua fase ini dan karena seringkali seseorang berpindah dari aktivitas choice ke aktivitas design.

Fase ini meliputi aktivitas mencari, mengevaluasi dan merekomendasikan sebuah solusi yang sesuai dengan model. Solusi terhadap sebuah model adalah sekumpulan nilai untuk beberapa variabel keputusan dalam sebuah alternatif terpilih.

4. Fase Implementation

Dalam fase ini, sebuah tindakan dilakukan sebagai bentuk realisasi dari pemilihan sebuah solusi dari masalah yang ada.

\section{Artificial Intelligence}

Komputer pada awalnya lebih didefinisikan sebagai alat untuk melakukan penghitungan. Sejalan dengan perkembangan zaman dan makin beragamnya aktivitas manusia, maka komputer diharapkan mampu melakukan aktivitas yang juga dilakukan manusia. Inilah yang kemudian menjadi cikal bakal terbentuknya Kecerdasan Buatan (Artificial Intelligence atau Al). Mengingat bahwa manusia menjadi cerdas karena dibekali dengan pengetahuan, penalaran dan pengalaman, maka agar kinerja komputer dapat bertindak sebaik manusia, komputerpun dibekali dengan kecerdasan dan kemampuan nalar.

Tingkat kecerdasan yang dimaksud adalah berupa: mengurai bentuk permasalahan berdasarkan kriterianya, mengolah data-data dan melakukan tindakan apa yang harus dilakukan sesuai dengan pengalaman yang telah diperoleh (diajarkan), dan mampu menerima kepakaran seorang ahli melalui perintah yang dituliskan dalam sebuah bahasa pemrograman tertentu. Aplikasi ini banyak dimanfaatkan untuk keperluan ekonomi, konstruksi, maupun industri.

\section{Sistem Pakar (Expert System)}

Sistem pakar adalah salah satu cabang dari Al yang membuat penggunaan secara luas knowledge yang khusus untuk penyelesaian masalah tingkat manusia yang pakar. (Arhami, 2005:3). Sistem pakar (SP) merupakan suatu sistem yang berusaha mengadopsi pengetahuan manusia ke komputer agar komputer dapat menyelesaikan masalah seperti yang bisa dilakukan para ahli. Sistem pakar ini dapat berisi lebih dari satu dengan pengetahuan (knowledge) yang dapat berupa:

a. Fakta kejadian pada lingkup suatu permasalahan,

b. Prosedur yang terkait dengan lingkup suatu permasalahan,

c. Strategi untuk menyelesaikan suatu permasalahan maupun

d. Meta-knowledge (pengetahuan mengenai suatu pengetahuan).

Pengetahuan ini terkumpul dalam suatu medium yang disebut sebagai basis data pengetahuan atau knowledge base, di mana fungsi dari basis data pengetahuan ini adalah sebagai dasar dalam menjawab pertanyaan (konsultasi). Sedangkan untuk menganalisis pengetahuan dan menarik kesimpulan berdasarkan basis data pengetahuan tersebut dilakukan oleh subsistem yang disebut motor inferensi atau inference engine. 


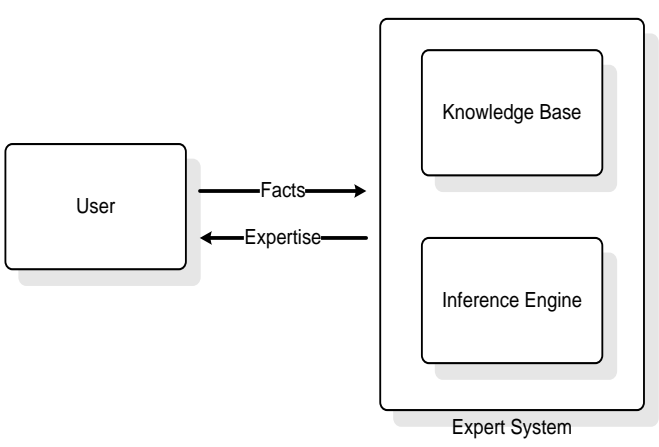

Gambar 2.1 Diagram pada sistem pakar

\section{Logika Fuzzy}

Logika fuzzy merupakan salah satu komponen pembentuk soft computing. Logika fuzzy pertama kali diperkenalkan oleh Prof Lofti A. Zadeh pada tahun 1965. Dasar logika fuzzy adalah teori himpunan fuzzy. Menurut Kusumadewi (2010:1) "Pada teori himpunan fuzzy, peranan derajat keanggotaan sebagai penentu keberadaan elemen dalam suatu himpunan sangatlah penting". Nilai keanggotaan atau derajat keanggotaan atau membership function menjadi ciri utama dari penalaran logika fuzzy tersebut.

\section{Metode Sugeno}

Metode ini digagas oleh Takagi Sugeno Kang pada tahun 1985, sehingga metode ini sering juga dinamakan dengan Metode TSK. Menurut Kusumadewi (2010:46) "Penalaran dengan metode SUGENO hampir sama dengan penalaran MAMDANI, hanya saja output (konsekuen) sistem tidak berupa himpunan fuzzy, melainakan berupa konstanta atau persamaan linear". Metode Sugeno terdiri atas dua bagian, yaitu Metode Sugeno Orde 0 dan Metode Sugeno Orde 1. Apabila komposisi aturan menggunakan metode SUGENO, maka deffuzifikasi dilakukan dengan cara mencari nilai rataratanya.

\section{Matlab Toolbox : Fuzzy}

Agar dapat menggunakan fungsi-fungsi logika fuzzy yang ada pada MATLAB, maka harus diinstal terlebih dahulu TOOLBOX
FUZZY. Fuzzy logic toolbox memberikan fasilitas Graphical User Interface (GUI) untuk mempermudah dalam membangun suatu system fuzzy.

Ada 5 GUI tools yang dapat digunakan untuk membangun, mengedit, dan mengobservasi system penalaran fuzzy, yaitu:
a. Fuzzy Inference System (FIS) Editor
b. Membership Function Editor
c. Rule Editor
d. Rule Viewer
e. Surface Viewer

\section{F. PEMBAHASAN}

Berdasarkan data penjualan dari masingmasing wilayah maka akan digabungkan sehingga akan didapatkan data keseluruhan dari PT. Guardian Pharmatama. Data yang diambil adalah data variabel permintaan barang dan persediaan barang bulan Januari tahun 2010 sampai dengan bulan Desember tahun 2012.

Tabel 1. Data Permintaan dan Persediaan Fungasol SS Shampo Januari 2010 sampai dengan Desember 2012 
a. PT GUARDIAN PHARMATAMA TANGERANG

\begin{tabular}{|l|c|c|c|c|}
\hline \multicolumn{1}{|c|}{ BULAN } & TAHUN & $\begin{array}{c}\text { PERMINTAAN } \\
\text { PRODUKSI (Shipper) }\end{array}$ & PERSEDIAN (Shipper) & PRODUKSI (Shipper) \\
\hline JANUARI & 2010 & 4230 & 300 & 4250 \\
\hline FEBRAARI & 2010 & 3951 & 200 & 3960 \\
\hline MARET & 2010 & 2500 & 150 & 2550 \\
\hline APRIL & 2010 & 3870 & 200 & 3890 \\
\hline MEI & 2010 & 3500 & 280 & 3550 \\
\hline JUNI & 2010 & 4750 & 230 & 4760 \\
\hline JULI & 2010 & 5031 & 500 & 5050 \\
\hline AGUSTUS & 2010 & 5230 & 290 & 5250 \\
\hline SEPTEMBER & 2010 & 4950 & 350 & 5000 \\
\hline OKTOBER & 2010 & 4632 & 480 & 4650 \\
\hline NOVEMBER & 2010 & 4578 & 450 & 4580 \\
\hline DESEMBER & 2010 & 4330 & 410 & 4350 \\
\hline JANUARI & 2010 & 5026 & 530 & 5030 \\
\hline FEBRUARI & 2011 & 5025 & 510 & 5030 \\
\hline MARET & 2011 & 4580 & 460 & 4250 \\
\hline APRIL & 2011 & 5230 & 600 & 4250 \\
\hline MEI & 2011 & 5078 & 510 & 3960 \\
\hline JUNI & 2011 & 4500 & 150 & 2550 \\
\hline JULI & 2011 & 3870 & 280 & 3890 \\
\hline AGUSTUS & 2011 & 3025 & 350 & 3550 \\
\hline SEPTEMBER & 2011 & 4750 & 230 & 4760 \\
\hline OKTOBER & 2011 & 5031 & 500 & 5050 \\
\hline NOVEMBER & 2011 & 5230 & 290 & 5250 \\
\hline DESEMBER & 2011 & 4980 & 350 & 5000 \\
\hline JANUARI & 2012 & 4632 & 480 & 4650 \\
\hline FEBRUARI & 2012 & 4578 & 450 & 4580 \\
\hline MARET & 2012 & 4330 & 410 & 4350 \\
\hline APRIL & 2012 & 5026 & 530 & 5030 \\
\hline MEI & 2012 & 5025 & 510 & 5030 \\
\hline JUNI & 2012 & 4580 & 460 & 4250 \\
\hline JULI & 2012 & 4578 & 450 & 4580 \\
\hline AGUSTUS & 2012 & 4330 & 410 & 4350 \\
\hline SEPTEMBER & 2012 & 5226 & 530 & 5030 \\
\hline OKTOBER & 2012 & 5025 & 510 & 5030 \\
\hline NOVEMBER & 2012 & 5580 & 560 & 5590 \\
\hline DESEMBER & 2012 & 6580 & 660 & \\
\hline & & & & \\
\hline
\end{tabular}

Data diatas selanjutnya dipilih untuk dipergunakan sebagai variabel masukan untuk sistem pendukung keputusan. Pengolahan dari data yang dikumpulkan dilakukan dengan membentuk fungsi dari variabel-variabel yang ada, yaitu fungsi Input dengan variabelnya Permintaan dan Persediaan, serta fungsi Output dengan variabel Produksi.

\section{Himpunan Semesta Pembicaraan dan Himpunan Variabel Input}

Variabel yang terkait dalam proses yang akan ditentukan dan fungsi fuzzifikasi yang sesuai, ada 3 variabel yang akan dimodelkan, yaitu:

Tabel 2.Penentuan Variabel dan Semesta

Pembicaraan

Fungasol SS Shampo

\begin{tabular}{|c|c|c|l}
\hline Fungsi & Nama Variabel & Semesta pembicaraan & \multicolumn{1}{|c}{ Keterangan } \\
\hline \multirow{2}{*}{ Input } & Permintaan & {$[1000-6580]$} & $\begin{array}{l}\text { Jumlah pemesanan produk perbulan } \\
\text { (Shipper) }\end{array}$ \\
\cline { 2 - 4 } & Persediaan & {$[100-660]$} & $\begin{array}{l}\text { Jumlah persediaan produk perbulan } \\
\text { (Shipper) }\end{array}$ \\
\hline Output & Produksi & {$[1000-6600]$} & $\begin{array}{l}\text { Jumlah produksi produk perbulan } \\
\text { (Shipper) }\end{array}$ \\
\hline
\end{tabular}

Pada tabel diatas, dapat dikelompokkan berdasarkan besarnya nilai yang ada pada setiap variabel sehingga kita dapat mengetahui berapa nilai minimum dan maksimum dari variabel-variabel yang digunakan selama 3 tahun terakhir.

Tabel 3. Himpunan Fuzzy Fungasol SS Shampo

\begin{tabular}{|c|c|c|c|c|}
\hline Fungsi & Variabel & Himpunan Fuzzy & $\begin{array}{l}\text { Semesta Pembicaraan } \\
\text { (Shipper) }\end{array}$ & Domain (Shipper) \\
\hline \multirow[t]{6}{*}{ Input } & \multirow{3}{*}{ Permintaan } & Turun & \multirow{3}{*}[1000-6580]{} & {$[1000-3000]$} \\
\hline & & Biasa & & [2500 - 3500] \\
\hline & & Naik & & [3000 - 6580] \\
\hline & \multirow{3}{*}{ Persediaan } & Sedikit & \multirow{3}{*}{ [100 - 660] } & [100 - 300] \\
\hline & & Sedang & & [200 - 400] \\
\hline & & Banyak & & [300 - 660] \\
\hline \multirow[t]{3}{*}{ Output } & \multirow{3}{*}{ Produksi } & Berkurang & \multirow{3}{*}{ [1000 - 6600] } & [1000 - 3000] \\
\hline & & Normal & & [2000 - 4000] \\
\hline & & Bertambah & & [3000 - 6600] \\
\hline
\end{tabular}

\section{Fungsi Keanggotaan Himpunan pada Variabel Input}

a. Permintaan (x), terdiri atas 3 himpunan fuzzy, yaitu TURUN, BIASA dan NAIK

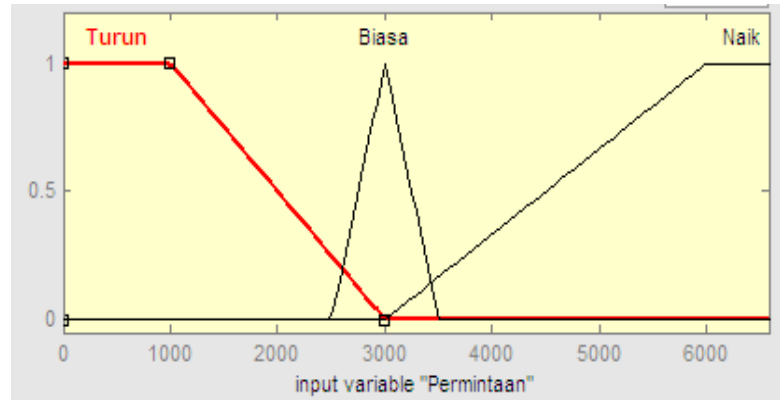

Gambar 1. Himpunan Fuzzy

Permintaan

Dengan fungsi keanggotaan adalah sebagai

berikut:

$$
\mu \operatorname{Turun}(x)=\left\{\begin{array}{cc}
1 \quad ; x \leq 1000 \\
\frac{3000-x}{2000} ; 1000 \leq x \leq 3000 \\
0 ; x \geq 3000
\end{array}\right.
$$




$$
\begin{aligned}
& \mu \text { Biasa }(x)=\left\{\begin{array}{cc}
0 & ; x \leq 2500 \text { atau } x \geq 35 \\
\frac{x-2500}{500} & ; 2500 \leq x \leq 3000 \\
\frac{3500-x}{500} & ; 3000 \leq x \leq 3500 \\
1 \quad & ; x \geq 3500
\end{array}\right. \\
& \mu \text { Naik }(x)=\left\{\begin{array}{cc}
0 & ; x \leq 3000 \\
\frac{x-3000}{3580} & ; 3000 \leq x \leq 6580 \\
1 & ; x \geq 6580
\end{array}\right.
\end{aligned}
$$

b. Persediaan (y), terdiri atas 3 himpunan fuzzy, yaitu SEDIKIT, SEDANG dan BANYAK

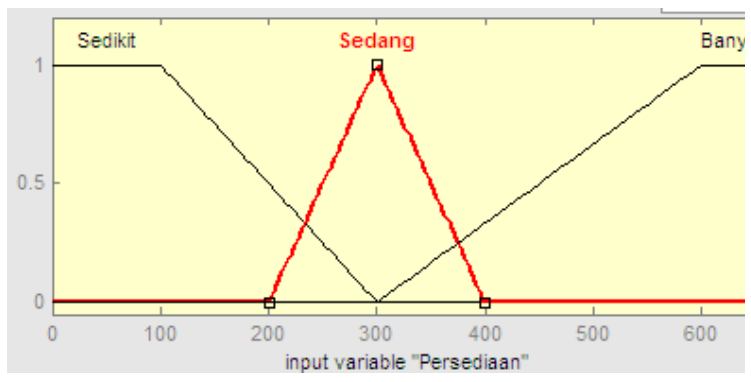

Gambar 2. Himpunan Fuzzy

Variabel Persediaan

Dengan fungsi keanggotaan adalah sebagai berikut:

$$
\mu \text { Sedikit }(y)=\left\{\begin{array}{ccc}
1 & ; & x \leq 100 \\
\frac{300-y}{200} & ; & 100 \leq x \leq 300 \\
0 & ; & y \geq 300
\end{array}\right.
$$

$\mu$ Sedang $(y)=\left\{\begin{array}{cc}0 ; y \leq 200 \text { atau } y \geq 400 \\ \frac{y-200}{200} ; 200 \leq x \leq 300 \\ \frac{400-y}{100} ; & ; 00 \leq x \leq 400 \\ 1 \quad & ; y \geq 400\end{array}\right.$

$\mu \operatorname{Banyak}(y)=\left\{\begin{array}{cc}0 & ; y \leq 300 \\ \frac{y-300}{360} & ; 300 \leq y \leq 660 \\ 1 & ; y \geq 660\end{array}\right.$

C. Produksi $(\mathrm{z})$, terdiri atas 3 himpunan fuzzy, yaitu BERKURANG, NORMAL dan BERTAMBAH

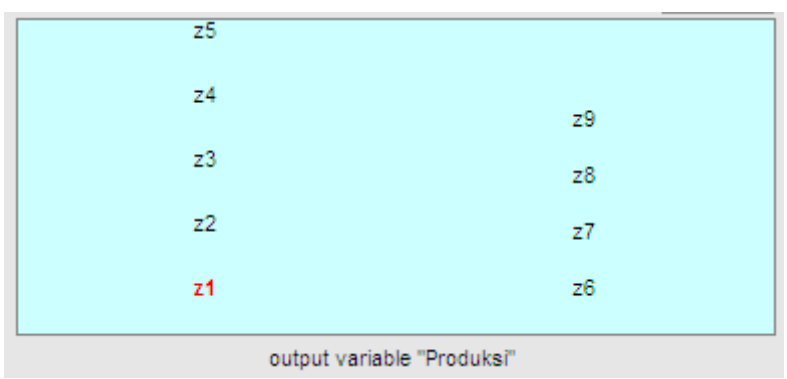

Gambar 3. Himpunan Fuzzy Variabel

Produksi

\section{Pembentukan Rule}

Rule IF-THEN dibuat dengan mengkombinasikan beberapa kejadian pada bagian anteseden. Penentu koefisien dan konstanta persamaan linierpada bagian konsekuen ditentukan sedemikian sehingga dapat menghasilkan jumlah 
produksi yang sesuai dengan keadaan perusahaan.

Hasil pembentukan rule sebagai berikut:

[R1] Jika Permintaan TURUN dan Persediaan SEDIKIT maka (Z1) Produksi = Permintaan

[R2] Jika Permintaan TURUN dan Persediaan SEDANG maka (Z2) Produksi = Permintaan

[R3] Jika Permintaan TURUN dan Persediaan BANYAK maka (Z3) Produksi = Permintaan - Persediaan

[R4] Jika Permintaan BIASA dan Persediaan SEDIKIT maka (Z4) Produksi = Permintaan

[R5] Jika Permintaan BIASA dan Persediaan SEDANG maka (Z5) Produksi = Permintaan

[R6] Jika Permintaan BIASA dan Persediaan BANYAK maka (Z6) Produksi = Permintaan

[R7] Jika Permintaan NAIK dan Persediaan SEDIKIT maka (Z7) Produksi $=1,25$ * Permintaan - Persediaan

[R8] Jika Permintaan NAIK dan Persediaan SEDANG maka (Z8) Produksi = Permintaan

[R9] Jika Permintaan NAIK dan Persediaan BANYAK maka (Z9) Produksi = Permintaan - Persediaan

\section{Aplikasi Fungsi Implikasi}

Jika diketahui permintaan sebanyak 4230 shipper, maka :

$$
\underset{(4230)}{\mu \text { Turun }}=0
$$

$\mu$ Biasa (4230) $=0$

$$
\mu \text { Naik }(4230)=\frac{4230-3000}{3580}=0,34
$$

dan jika diketahui persediaan sebanyak 210 shipper, maka :

$$
\mu \text { Sedikit }(300)=0
$$

$$
\mu \text { Sedang }(300)=\frac{300-200}{200}=0,5
$$

$$
\mu \text { Banyak }(300)=0
$$

Maka a-predikat dan nilai Z untuk masing-masing aturan :

[R1] Jika Permintaan TURUN dan

$$
\text { Persediaan SEDIKIT maka }
$$

(Z1) Produksi = Permintaan

$\alpha$ - predikat $1=\mu$ PmtTURUN $\cap$ $\mu$ PsdSEDIKIT

$=\min (\mu \mathrm{PmtTUR}$

UN(4230), $\mu$ PsdSEDIKIT

$$
=\min (0 ; 0)=0
$$

sehingga didapatkan nilai $\mathrm{Z1}=$ 4230

[R2] Jika Permintaan TURUN dan Persediaan SEDANG maka 
(Z2) Produksi = Permintaan

a- predikat2 $=\mu$ PmtTURUN $\cap$ $\mu$ PsdSEDANG

$=\min (\mu \mathrm{PmtTUR}$

UN(4230), $\mu$ PsdSEDANG

$$
=\min (0 ; 0,5)=0
$$

sehingga didapatkan nilai $\mathbf{Z 2}=$ 4230

[R3] Jika Permintaan TURUN dan Persediaan BANYAK maka

(Z3) Produksi = Permintaan -

Persediaan

$$
\begin{aligned}
\alpha-\text { predikat } 3= & \mu \text { PmtTURUN } \cap \\
& \mu \text { PSdBANYAK }
\end{aligned}
$$$$
=\min (\mu \mathrm{PmtTUR}
$$$$
\text { UN(4230), }
$$$$
\text { MPsdBANYAK }
$$

$$
=\min (0 ; 0)=0
$$

sehingga didapatkan nilai

$\mathrm{Z3}=4230-300=3930$

[R4] Jika Permintaan BIASA dan Persediaan SEDIKIT maka

(Z4) Produksi $=$ Permintaan

$$
\begin{array}{ll}
\alpha-\operatorname{predikat} 4= & \mu \text { PmtBIASA } \cap \\
& \mu \text { PsdSEDIKIT } \\
=\min & \\
& (\mu \text { PmtBIASA }(42 \\
& 30),
\end{array}
$$

$\mu$ PsdSEDIKIT

$$
=\min (0 ; 0)=0
$$

sehingga didapatkan nilai Z4 = 4230

[R5] Jika Permintaan BIASA dan Persediaan SEDANG maka

(Z5) Produksi $=$ Permintaan

a- predikat5 $=\mu$ PmtBIASA $\cap$ $\mu$ PsdSEDANG $=\min$

$(\mu \mathrm{PmtBIASA}(42$

30),

$\mu$ PsdSEDANG

$$
=\min (0 ; 0,50)=0
$$

sehingga didapatkan nilai $Z 5=$ 4230

[R6] Jika Permintaan BIASA dan Persediaan BANYAK maka

(Z6) Produksi $=$ Permintaan

$\alpha$ - predikat6 $=\mu$ PmtBIASA $\cap$ PPSdBANYAK

$$
=\min
$$

( $\mu$ PmtBIASA(4980)

$$
\begin{gathered}
, \quad \mu \text { PsdBANYAK } \\
(150)) \\
=\min (0 ; 0)=0
\end{gathered}
$$

sehingga didapatkan nilai $Z 6=$ 4230

[R7] Jika Permintaan NAIK dan Persediaan SEDIKIT maka 
(Z7) Produksi $=1,25$ * Permintaan -

Persediaan

$\alpha$ - predikat7 $=\mu$ PmtNAIK $\cap$ $\mu$ PsdSEDIKIT

$=\min (\mu \mathrm{PmtNAIK}(4230)$, $\mu$ PsdSEDIKIT (300))

$$
=\min (0,34 ; 0)=0
$$

sehingga didapatkan nilai

$Z 7=1,25 * 4230-300=4987,5$

[R8] Jika Permintaan NAIK dan Persediaan SEDANG maka

(Z8) Produksi $=$ Permintaan

$\alpha$ - predikat8 $=\mu$ PmtNAIK $\cap$ $\mu$ PsdSEDANG

$$
={ }_{(\mu \operatorname{PmtNAIK}(4230),} \text { min }
$$
$\mu$ PsdSEDANG (300))$$
=\min (0,34 ; 0,50)=
$$

sehingga didapatkan nilai Z8 = 4230

[R9] Jika Permintaan NAIK dan Persediaan BANYAK maka

(Z9) Produksi = Permintaan Persediaan

$$
\begin{gathered}
\alpha-\quad \text { predikat9 }=\mu \begin{array}{r}
\mu \text { PmtNAIK } \cap \\
\mu \text { PsdBANYAK }
\end{array} \\
=\min \quad(\mu \text { PmtNAIK }(4230), \\
\mu \text { PsdBANYAK }(300)) \\
=\min (0,34 ; 0)=0
\end{gathered}
$$

sehingga didapatkan nilai

$Z 9=4230-300=3930$
Hasil aplikasi fungsi implikasi tiap aturan, digunakan metode MIN untuk melakukan komposisi antara semua aturan. Setelah komposisi antar semua aturan dilakukan maka akan didapatkan output memalui langkah defuzzifikasi, untuk mempermudah dapat mengunakan toolbox pada Matlab yang digambarkan sebagai berikut:

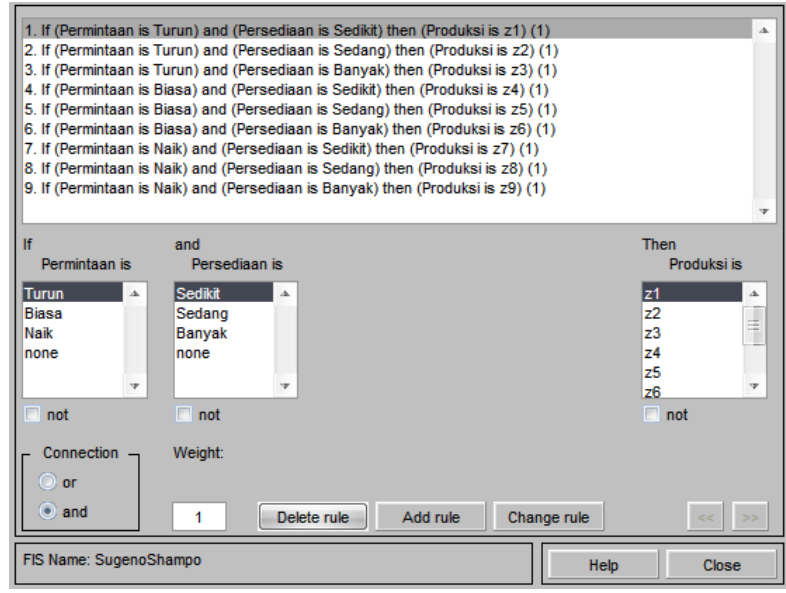

Gambar 4. Komposisi Aturan Metode Sugeno

Defuzzifikasi

Output atau produksi Fungasol SS

Shampoo untuk bulan Januari tahun 2013

Jumlah permintaan $=4980$ shipper

Jumlah persediaan $=150$ shipper

Selanjutnya untuk memperoleh nilai kesimpulan dari defuzzifikasi, digunakan metode rata-rata terpusat fuzzifikasi.

$$
Z_{0}=\frac{\sum_{i=1}^{9} \propto i Z i}{\sum_{i=1}^{9} \alpha_{i}}
$$

maka diperoleh banyaknya Fungasol SS Shampoo yang harus diproduksi pada bulan Januari 2013 adalah:

\section{Komposisi Aturan}




$$
\begin{aligned}
& Z_{0}= \frac{\sum_{i=1}^{9} \propto i Z i}{\sum_{i=1}^{9} \propto i} \\
&= \underline{0,34^{*} 4230} \\
& Z=4230
\end{aligned}
$$

Penalaran fuzzy menggunakan program simulasi yang disediakan fasilitasnya oleh Toolbox Fuzzy Matlab, ditunjukkan pada Gambar dibawah ini
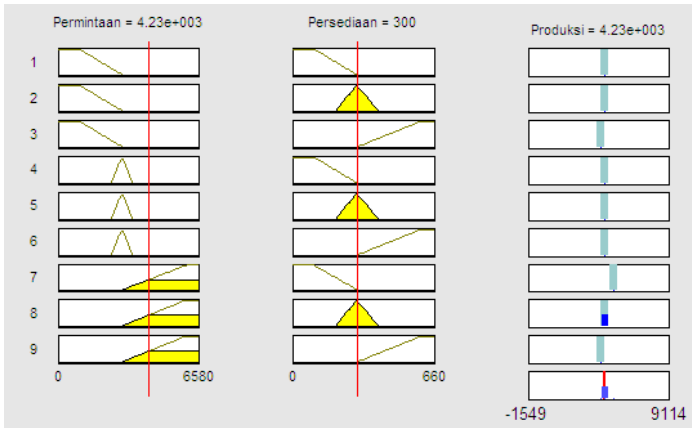

Gambar 5. Penalaran logika fuzzy

\section{Output Hasil Agregasi}

Data dari perusahaan terkait dengan jumlah produksi barang pada periode Januari - Desember tahun 2010 dibandingkan dengan hasil pengolahan

\begin{tabular}{|c|c|c|c|c|c|}
\hline BULAN & TAHUN & $\begin{array}{l}\text { PERMINTAAN } \\
\text { PRODUKSI } \\
\text { (Shipper) }\end{array}$ & $\begin{array}{l}\text { PERSEDIAN } \\
\text { (Shipper) }\end{array}$ & $\begin{array}{c}\text { PRODUKSI } \\
\text { PERUSAHAAN } \\
\text { (Shipper) }\end{array}$ & $\begin{array}{l}\text { Perhitungan Jumlah } \\
\text { Produksi Dengan } \\
\text { Metode } \\
\text { Sugeno }\end{array}$ \\
\hline JANUARI & 2010 & 4230 & 300 & 4250 & 4230 \\
\hline FEBRUARI & 2010 & 3951 & 200 & 3960 & 4740 \\
\hline MARET & 2010 & 2500 & 150 & 2550 & 2500 \\
\hline APRIL & 2010 & 3870 & 200 & 3890 & 4640 \\
\hline MEI & 2010 & 3500 & 280 & 3550 & 3570 \\
\hline JUNI & 2010 & 4750 & 230 & 4760 & 5270 \\
\hline JULI & 2010 & 5031 & 500 & 5050 & 4530 \\
\hline AGUSTUS & 2010 & 5230 & 290 & 5250 & 5280 \\
\hline SEPTEMBER & 2010 & 4950 & 350 & 5000 & 4860 \\
\hline OKTOBER & 2010 & 4632 & 480 & 4650 & 4150 \\
\hline NOVEMBER & 2010 & 4578 & 450 & 4580 & 4130 \\
\hline DESEMBER & 2010 & 4330 & 410 & 4350 & 3920 \\
\hline
\end{tabular}
data dengan mengunakan metode Sugeno, sebagai berikut:

Tabel 3. Data Produksi Fungasol SS Shampo

\section{Perancangan Sistem Aplikasi dan GUI}

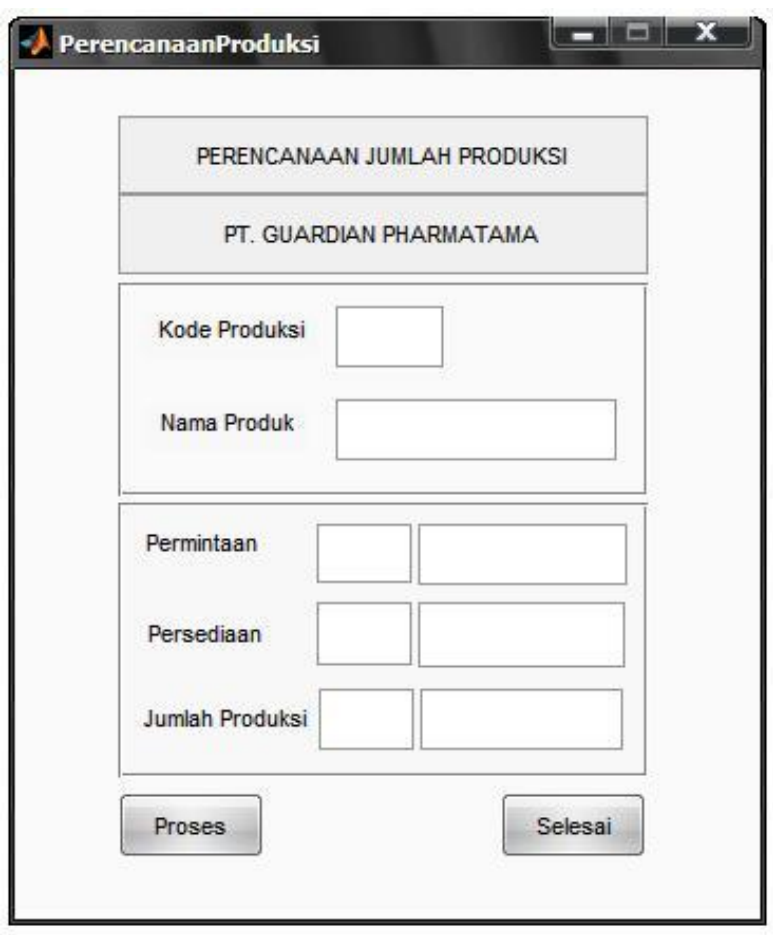

Gambar 6.Sistem Pendukung Keputusan

Penentuan Jumlah Produksi

\section{G. KESIMPULAN DAN SARAN}

\section{KESIMPULAN}

Setelah melakukan penelitian ini, maka dapat diambil beberapa kesimpulan sebagai berikut : 
1. Penggunaan logika fuzzy pada sistem yang nilai inputnya tidak pasti mampu menghasilkan output crisp, karena logika fuzzy memiliki toleransi terhadap data-data yang tidak tepat.

2. Setelah dilakukan pengolahan dengan metode Sugeno maka didapatkan output berupa produksi barang yaitu:

Pada bulan Januari, pada data produksi perusahaan adalah 4.250

Data produksi metode Sugeno adalah 4.230

3. Penggunaan Metode Sugeno pada bilangan Fuzzy dapat memperkirakan jumlah produksi Shampo Fungasol SS setiap bulannya.

\section{SARAN}

Saran-saran yang dapat disampaikan terkait dengan hasil penelitian ini adalah

1. Untuk pengembangan lebih lanjut terhadap sistem ini, disarankan untuk dilakukan penambahan beberapa variabel seperti variabel biaya, waktu, dan lain lain agar mendapatkan hasil yang lebih optimal.

2. Pembuatan GUI tidak hanya sebagai alat perhitungan tetapi juga disertai database sehingga data yang telah diinput dapat tersimpan dan dapat ditampilkan dalam bentuk laporan.

3. Dalam penelitian lain dapat diubah penggunaan metode FIS menjadi ANFIS

\section{DAFTAR REFERENSI}

[1]. Away, Gunaidi Abdia. 2010. MATLAB Programming Edisi Revisi. Bandung. INFORMATIKA

[2]. Djunaidi. Moch, dkk. 2005. Penentuan Jumlah Produksi Dengan Aplikasi Metode Fuzzy - Mamdani. Surakarta

[3]. Jogiyanto HM. 2005. Analisa dan Desain Sistem Informasi: Pendekatan Terstruktur Teori dan Praktek Aplikasi Bisnis. Yogyakarta. Andi Offset.

[4]. Kusumadewi, Sri, dan Purnomo, Hari (2010), Aplikasi Logika Fuzzy untuk Pendukung Keputusan, Yogyakarta, Graha IImu.

[5]. Kusumadewi, Sri, dan Hartati, Sri (2010), Neuro-Fuzzy Integrasi Sistem
Fuzzy \& Jaringan Syaraf Edisi 2, Yogyakarta, Graha IImu

[6]. Kusumadewi, Sri, dan Hartati, Sri. 2002 Analis dan Desain Sistem Fuzzy Menggunakan Toolbox Matlab. Yogyakarta. Graha IImu

[7]. Marimin. 2004. Teknik dan aplikasi pengambilan keputusan kriteria majemuk. Jakarta, Grasindo.

[8]. McLeod Jr, Raymond. 2004. Sistem Informasi Manajemen. Jakarta. Prenhallindo.

[9]. Naba, Agus. 2009. Belajar Cepat Fuzzy Logic Menggunakan MATLAB. Yogyakarta. Andi Offset.

[10]. Simon, Alexander Herbert (1996), the Science of Artificial, Massaschusetts, Massaschusetts Institute of Technology.

[11]. Surbakti, Irfan, (2002). "Sistem Pendukung Keputusan", Surabaya, Jurusan Teknik Informatika, Fakultas Teknologi Informasi, Institut Teknologi Surabaya

[12]. Suwandi, Mohammad Isa Irawan, dan Imam Mukhlash. 2011. Aplikasi Sistem Inferensi Fuzzy Metode Sugeno Dalam Memperkirakan Produksi Air Mineral Dalam Kemasan. Yogyakarta. 